\title{
НОРМАТИВНО-ПРАВОВОЕ РЕГУЛИРОВАНИЕ ПРАВА НА СОЦИАЛЬНОЕ ОБЕСПЕЧЕНИЕ В ТЮМЕНСКОЙ ОБЛАСТИ
}

\begin{abstract}
Аннотация: В статье проводиться анализ законодательства в сфере сочииального обеспечения. Исследуются как нормы федерального законодательства, так нормативные акты тюменской области. Анализируется формирование законодательства субъекта Российской Федерачии - Тюменской области через призму разграничения компетенции между Российской Федерацией и ее субъектами при реализации конституциионного права граждан на социальное обеспечение. Автор дает краткую характеристику базовых законов и подзаконных актов, входящих в систему региональных нормативно-правовых актов права социильного обеспечения. Указанные вопросы исследуются с помощью логического и системного методов, анализа и синтеза, формальноюридического, сравнительно-правового и историко-сравнительного методов познания. На основе проведённого исследования сделан вывод о повышении роли субъектов Российской Федерации при реализации конституционного права граждан на социальное обеспечение, о необходимости детального закрепления разграничения компетенции между федеральными и региональными органами в области социального обеспечения с одновременным определением источников финансирования, показана необходимость дальнейшего развития региональной составляющей нормативно-правовой базы права на социальное обеспечение. Abstract: This article presents an analysis of the legislation in the area of social security. It researches both, the norms of federal legislation, as well as the normative acts of Tyumen Oblast. An analysis is conducted on the structuring of legislation of the Tyumen Oblast as a subject of Russian Federation through the prism of delimitation of the competency between the Russian Federation and its subjects in realization of the constitutional rights of citizens to social security. The author gives brief characteristics of the basic laws and by-laws that are part of the system of regional normative acts on the right to social security. Based on the conducted research a conclusion is drawn about the increase of the role of the subjects of Russian Federation in exercising the constitutional right of citizens to social security, and the need to have a detailed confirmation of delimitation of competency between the federal and regional authorities in the field of social security and determining the source of financing. Ключевые слова: Конституция, сочиальное государство, субъект Федерации, законодательство, соииальная политика, монетизация, компетенция, стандарты, органы власти, финансирование.
\end{abstract}

Keywords: Constitution, social state, subject of Federation, legislation, social policy, monetization, competency, standards, government authority, financing.

соответствии с пунктом «ж» части 1 статьи 72 Конституции Российской Федерации социальное обеспечение находится в совместном ведении Российской Федерации и субъектов Российской Федерации. Данное конституционное положение получило свое развитие в федеральном законодательстве, а именно в Федеральном законе от 06.10.1999 № 184-Ф3 (ред. от 22.10.2013) «Об общих принципах организации законодательных (представительных) и исполнительных органов государственной власти субъектов Российской Федерации», устанавливающем, в частности, распределение полномочий по обеспечению конституционного права на социальное обеспечение между органами государственной власти двух уровней.

Одним из направлений проводимой в России административной реформы является совершенствование разграничения полномочий между уровнями государственной власти. Результатом этих конституционно-правовых процессов стало расширение самостоятельности органов государственной власти субъектов Российской Федерации по регулированию общественных отношений в различных сферах, в т.ч. в системе социального обеспечения.

За субъектами Российской Федерации были закреплены полномочия социальной поддержки и социального обслуживания граждан пожилого возраста и инвалидов, граждан, находящихся в трудной жизненной ситуации, а также детей-сирот, безнадзорных детей, детей, оставшихся без попечения родителей (за исключением детей, обучающихся в федеральных образовательных учреждениях), социальной поддержки ветеранов труда, лиц, проработавших в тылу в период Великой Отечественной войны 1941 - 1945 годов, семей, имеющих детей (в том числе многодетных семей, одиноких родителей), жертв политических репрессий, малоимущих граждан.

Следовательно, отношения в указанной сфере подлежат урегулированию уже не только федеральными законами, но и законами субъектов Российской Федерации. Органы государственной власти субъектов Российской Федерации самостоятельно устанавливают социальное обеспечение, финансируемое из бюджетов субъектов Российской Федерации и территориальных государственных внебюджетных фондов, осуществляют иные полномочия, закрепленные за ними федеральными законами, а также регулируют отношения по социальному обеспечению, непосредственно не урегулированные федеральными законами. Представительные органы местного самоуправления самостоятельно устанавливают социальное обеспечение, финансируемое из местных бюджетов и муниципальных внебюджетных фондов.

По мнению О.О. Маленко, принцип естественного характера прав и свобод, закрепленный ч.2 ст.17 Конституции Российской Федерации, принцип открытого перечня прав и свобод человека и гражданина, установленный ч.1 ст.55 Конституции РФ, дают основания полагать, что федеральная Конституция формулирует презумпцию неограниченности субъектов, «творящих» права и свободы, фиксируя лишь приоритет Российской Федерации в установлении пределов допустимых ограничений прав и свобод человека и гражданина. ${ }^{1}$

\footnotetext{
${ }^{1}$ См.: Маленко О.О. Конституционное (уставное) закрепление прав и свобод человека и гражданина в субъектах Российской Федерации: Автореф.дис. ...канд. юрид.наук Ростов н/Д.,2002. С.8.
} 
DOI: $10.7256 / 1811-9018.2014 .12 .13698$

При цитировании этой статьи сноска на dоі обязательна

\section{Право и политика $12(180) \cdot 2014$}

Важное место в проведении разграничения компетенции между уровнями власти в сфере социального обеспечения занял Федеральный закон от 22.08.2004 года № 122-Ф3 «О внесении изменений в законодательные акты Российской Федерации и признании утратившими силу некоторых законодательных актов Российской Федерации в связи с принятием законов «О внесении изменений и дополнений в Федеральный закон «Об общих принципах организации законодательных (представительных) и исполнительных органов государственной власти субъектов Российской Федерации» и «Об общих принципах организации местного самоуправления в Российской Федерации» (далее- закон «о монетизации льгот»). Указанный закон преследовал несколько целей: во-первых, разграничение бюджетных полномочий между уровнями власти и, во -вторых, собственно сама реформа социальных льгот. В рамках концепции реформы социальных льгот перед законом ставилась задача ориентировать меры социальной поддержки на индивидуальные потребности граждан, усилить адресную социальную поддержку ветеранов, инвалидов путем замены существующих льгот, большая часть которых не обеспечена финансированием, на меры социальной адресной поддержки граждан путем введения ежемесячных денежных выплат, а также решить проблему механизма реализации льгот, поскольку «выделяемые средства превращались в неприкрытые дотации тем организациям, которые отвечали за непосредственное выполнение обязанности государственных и муниципальных органов по предоставлению социальных льгот»².

Однако, прежде всего, как следует из его названия, закон решал вопросы разграничения полномочий между федеральными органами государственной власти, органами государственной власти субъектов Российской Федерации и органами местного самоуправления. Поставленные перед законом «о монетизации льгот» задачи принципиально решены: ликвидированы не финансируемые льготы, получило адресность и индивидуализацию финансирование мер социальной поддержки, разграничены расходы по финансированию социальной помощи между федеральным и местным бюджетами.

Федеральный закон от 24.08.2004 № 122-Ф3 представляет собой основу всей концепции государственной социальной помощи в Российской Федерации, является одним из направлений осуществления и реализации конституционного права граждан на социальное обеспечение. После принятия указанного закона особенно важна детальная правовая регламентация и практическая реализация принципа разграничения предметов ведения и полномочий между органами государственной власти Российской Федерации и органами государственной власти субъектов Российской Федерации. Способом закрепления компетенций является конституционное разграничение предметов ведения Российской Федерации, её субъектов и определение сферы их совместного ведения (ст.ст.71,72 и 73 Конституции Российской Федерации), т.е. презюмируется конституционная модель разграничения компетенций, хотя развитие федерального законодательства в настоящее время и идет по пути ее транс-

${ }^{2}$ См.: Добрынин Н.М. Конституционно-правовые аспекты бюджетной обеспеченности реализации социальных гарантий граждан в Российской Федерации и проблема монетизации льгот // Право и политика. 2005. №11. С.4. формации. Конституцией Российской Федерации устанавливаются исключительная компетенция федерального центра, совместное ведение Российской Федерации и ее субъектов и остаточная компетенция субъектов Российской Федерации.

Правовой основой осуществления полномочий по региональному правотворчеству в сфере социального обеспечения, применительно к Тюменской области, являются указанные выше статьи Конституции Российской Федерации, Федеральный закон от 24.08.2004 № 122-Ф3 и ст. 5 Устава Тюменской области ${ }^{3}$.

Как уже было сказано выше, толчком к развитию в субъектах РФ законодательства о социальном обеспечении послужило принятие Ф3 №122-Ф3 от 22 августа 2004 г., который существенно расширил компетенцию субъектов РФ в данной сфере, поскольку им были переданы полномочия по самостоятельному правовому регулированию целого ряда общественных отношений по социальному обеспечению, которые прежде регулировались федеральным законодательством. Это повлекло за собой необходимость приведения регионального законодательства о социальном обеспечении в соответствие с новым федеральным правовым регулированием. ${ }^{4}$.

Законодательство Тюменской области о социальном обеспечении не стало исключением и с 1 января 2005 г. началась реализация данной реформы. Необходимо отметить, что, по данным Министерства финансов Российской Федерации, до 2005 г. только на федеральном уровне существовало около 120 видов льгот, которыми пользовалось свыше 200 категорий получателей ${ }^{5}$. Всего правом на льготы обладало более 103 млн. человек. Ими, в частности, пользовались около 20 млн. ветеранов труда, а также 5,2 млн. тружеников тыла ${ }^{6}$, которых затронула реформа. По статистическим данным, численность только ветеранов труда и тружеников тыла в Тюменской области в 2005 г. составляла 144043 человека7

Принципиальным вопросом введения в действие Закона от 22 августа 2004 г. являлось сохранение существующего уровня социальной защиты граждан, имеющих право на получение льгот. Данному вопросу были посвящены преамбула и ст. 153 этого Закона. В преамбуле установлено, что при переходе к системе социальной защиты граждан, основанной на положениях данного Закона, субъекты Российской Федерации и муниципальные образования должны вводить

\footnotetext{
${ }^{3}$ См.: Устав Тюменской области от 30.06.1995 № 6 // Тюменские известия, № 133, 15.07.1995.

${ }^{4}$ См.: Самарина O.A. Состояние законодательства о социальном обеспечении субъектов РФ: общий анализ// www.territoriaprava.ru.

${ }^{5}$ См.: Геворкьян Д.П. Становление законодательства Республики Дагестан о социальном обеспечении // Социальное и пенсионное право. 2012. № 2. C.30- 32 .

${ }^{6}$ См.: Штейнберг М. Горькие «уроки» монетизации льгот. Улучшится ли положение россиян // URL: http:// www.asi.org.ru/ ASI3/ main.nsf/ 0/ 702E418285403167C3257015002EFB93.

${ }^{7}$ См.: Численность категорий получателей, размеры денежных выплат и расходы региональных бюджетов 2004 г. и на введение «монетизации» льгот в 2005 г. // Мониторинг социальных аспектов реализации Закона от 22 августа 2004 г. N 122-Ф3 // Аналитический вестник Совета Федерации Федерального Собрания РФ. 2005. № 3. С. 77.
} 
Человек и государство

эффективные правовые механизмы, обеспечивающие сохранение и возможное повышение ранее достигнутого уровня социальной защиты граждан с учетом специфики их правового, имущественного положения, а также других обстоятельств. Статья 153 Закона от 22 августа 2004 г. установила норму общего характера, которая гарантирует, что граждане, ранее получавшие льготы в натуральной форме, теперь должны получить те же гарантии, но уже в новой форме, предусмотренной этим законом (т.е. преимущественно в форме денежной выплаты ${ }^{8}$.

Основным базовым нормативным правовым актом Тюменской области в ходе осуществления реформирования в сфере социальной поддержки населения стал Закон Тюменской области от 28.12.2004 №331 «О социальной поддержке отдельных категорий граждан в Тюменской области» (далее - Закон). Закон направлен на обеспечение сохранения и возможного повышения ранее достигнутого уровня социальной защиты граждан с учетом специфики их правового, имущественного положения, а также других обстоятельств. Указанный региональный Закон устанавливает меры социальной поддержки не только региональным льготникам, но и дополнительные - федеральным. Например, так дополнительно к мерам социальной поддержки, установленным федеральным законодательством, в отношении инвалидов, проживающих в Тюменской области, осуществляется возмещение расходов на оплату занимаемой общей площади жилых помещений независимо от формы собственности жилищного фонда в пределах регионального стандарта нормативной площади жилого помещения, используемой для предоставления социальной поддержки, в размере 50 процентов установленных тарифов - в отношении членов семей инвалидов, совместно с ними проживающих 9 . Указанная мера социальной поддержки предоставляется инвалидам, проживающим в жилых помещениях негосударственного и немуниципального жилищного фонда, в пределах регионального стандарта нормативной площади жилого помещения, используемой для предоставления социальной поддержки, в размере 50 процентов установленных тарифов. В 2013 году данная мера социальной поддержки предоставлена 53299 инвалидам, в 1 полугодии 2014 года - 54739 инвалидам. В Тюменской области инвалидам первой и второй группы осуществляется возмещение расходов на оплату единовременной установки квартирного проводного телефона в размере 50 процентов установленного тарифа. Кроме того, в соответствии с постановлением Правительства РФ от 25.09.2007 № 608 «О порядке предоставления инвалидам услуг по переводу русского жестового языка (сурдопереводу, тифлосурдопереводу)» ${ }^{10}$ проживающим в Тюменской

\footnotetext{
${ }^{8}$ См.: Геворкьян Д.П. Становление законодательства Республики Дагестан о социальном обеспечении // Социальное и пенсионное право. 2012. № 2. С. $30-32$.

${ }^{9}$ См. Закон Тюменской области от 28.12.2004 № 331 «О социальной поддержке отдельных категорий граждан в Тюменской области»// «Парламентская газета «Тюменские известия», № 280-281, 29.12.2004.

${ }^{10}$ См.: Постановление Правительства РФ от 25.09.2007 № 608 «О порядке предоставления инвалидам услуг по переводу русского жестового языка (сурдопереводу, тифлосурдопереводу)» // Собрание законодательства РФ, 01.10.2007, № 40, ст. 4798.
}

области инвалидам с нарушениями функций слуха предоставляются услуги по сурдопереводу в количестве 40 часов в течение года с даты подачи заявления. В 2013 году 335 человек заявителей обеспечены услугой сурдоперевода, в 2014 году - 63 человека.

Указанный областной Закон устанавливает также меры социальной поддержки детей-сирот, тружеников тыла, семей, имеющих детей, жертв политических репрессий, малоимущих граждан, участников вооруженных конфликтов, работников бюджетной сферы.

Отдельно хотелось бы отметить, что в рамках реализации Закона в Тюменской области предоставляются дополнительные меры социальной поддержки: адресная социальная помощь в виде адресного социального пособия малоимущим семьям и малоимущим одиноко проживающим гражданам, которые по независящим от них причинам имеют среднедушевой доход ниже установленной по Тюменской области величины прожиточного минимума на душу населения. По состоянию на 01.07.2014 адресная социальная помощь предоставлена 31,8 тыс. человек, в 2013 г. - 45,2 тыс. человек.

Основываясь на базовом нормативном правовом акте, Законе Тюменской области от 28.12.2004 №331 «О социальной поддержке отдельных категорий граждан в Тюменской области», в Тюменской области в 2005 году началось формирование регионального законодательства о социальном обеспечении. В ходе разработки и формирования нормативной правовой базы отрасли «Социальная политика» в Тюменской области активно используется бланкетный метод регулирования, когда основные меры социальной поддержки устанавливаются законом, а порядок назначения и основания их выплаты определяются Правительством региона.

В течение 2005 года в Тюменской области было принято свыше ста нормативных правовых актов, регламентирующих сферу социального обеспечения населения, проживающего в Тюменской области. Положительными чертами применяемого бланкетного способа регулирования права социального обеспечения на территории Тюменской области является, прежде всего, оперативность реагирования на изменяющиеся потребности как населения, так и государства в части установления той или иной меры социальной поддержки для решения определенных задач. Так, например, с целью решения вопроса кадрового обеспечения организаций образования и здравоохранения на территории отдельных муниципалитетов, Правительством области было принято постановление от 28.04.2005 № 18-П «О дополнительных мерах социальной поддержки отдельных категорий граждан, связанных с обеспечением получения ими жилья», что позволило в кратчайшие сроки, в том числе и благодаря возмещению расходов за найм жилья, решить вопросы привлечения молодых специалистов в социальную сферу.

Одним из применяемых способов разграничения полномочий в сфере реализации конституционного права граждан на социальное обеспечение является возможность заключения соглашения между федеральными органами государственной власти и органами государственной власти субъектов Российской Федерации. Так в настоящее время на территории Тюменской области в соответствии с Соглашением между Министерством здравоохранения и социального развития Российской Федерации и Правительством Тюменской области о передаче Правительству Тюменской области 
DOI: $10.7256 / 1811-9018.2014 .12 .13698$

При цитировании этой статьи сноска на doi обязательна

\section{Право и политика $12(180) \cdot 2014$}

осуществления части полномочий Российской Федерации по предоставлению мер социальной защиты инвалидам и отдельным категориям граждан из числа ветеранов, а также по оказанию государственной социальной помощи в виде социальных услуг по предоставлению при наличии медицинских показаний путевок на санаторно-курортное лечение и бесплатного проезда на междугородном транспорте к месту лечения и обратно от 20.12.2010 № 76 реализуются отдельные федеральные полномочия. В целях реализации указанных полномочий в рамках собственной компетенции Правительством Тюменской области принято постановление от 30.12.2010 № 394-п «О порядке осуществления переданных федеральных полномочий по предоставлению мер социальной защиты инвалидам и отдельным категориям граждан из числа ветеранов, а также по оказанию государственной социальной помощи в виде социальных услуг по предоставлению при наличии медицинских показаний путевок на санаторно-курортное лечение и бесплатного проезда на междугородном транспорте к месту лечения и обратно». Таким образом, осуществлено достаточное правовое регулирование разграничения компетенции между Российской Федерацией и ее субъектом по вопросу реализации конституционного права граждан на социальное обеспечение в части указанных выше полномочий.

Отдельно хотелось бы отметить формирование нормативной правовой базы, связанной с вступлением с 01.01.2015 года Федерального закона от 28.12.2013 № 442-Ф3 «Об основах социального обслуживания граждан в Российской Федерации». В Тюменской области проведена необходимая работа по разработке нормативной правовой базы и на основе действующих нормативных и правовых актов: принято 24 нормативных правовых акта; два проекта закона Тюменской области «Об утверждении перечня социальных услуг, предоставляемых поставщиками социальных услуг» и «Об установлении предельной величины среднедушевого дохода для предоставления социальных услуг бесплатно» внесены на рассмотрение в Тюменскую областную Думу, уже действуют 5 нормативных правовых актов; приняты и вступят в силу с 01.01.2015г. 12 нормативных правовых актов Правительства Тюменской области, а также 7 правовых актов уполномоченного органа- Департамента социального развития Тюменской области.

Таким образом, в течение 2005 года и по настоящее время на территории Тюменской области была сформирована и обновляется необходимая правовая база для осуществления полномочий в сфере социальной поддержки и социального обслуживания населения.

Одним из самых дискуссионных вопросов регионального, да и федерального законотворчества при формировании отраслевого законодательства социального обеспечения остается низкий уровень его кодификации. В системе источников права социального обеспечения нет единого, законодательно закрепленного свода принципиальных положений, что не позволяет последовательно развивать эту отрасль законодательства и права и, напротив, создает благодатную почву для его частых изменений в силу финансовых и иных конъюнктурных обстоятельств ${ }^{11}$. ${ }^{11}$ См.: Васильева Ю.В. О правовой политике в сфере права социального
обеспечения // Трудовое право в России и за рубежом. 2012. № 4. С. 23-26.
В этой связи весьма актуальным становится вопрос систематизации права на социальное обеспечение. Сама по себе данная тема не нова и поднималась неоднократно различными исследователями. О необходимости кодификации законодательства о социальном обеспечении на страницах юридических изданий говорилось неоднократно, но перевести научные дебаты в практическую плоскость до сих пор не удавалось. Задача кодификации законодательства о социальном обеспечении требует решения многих концептуальных вопросов, один из которых касается формы кодифицированного акта ${ }^{12}$. Известно, что в результате кодификации законодательства обычно создаются кодексы, другим видом сводного кодификационного акта являются уставы и положения, а также могут быть признаны некоторые конституционные и Федеральные законы. В Советском Союзе широкое распространение имел вид кодифицированного акта - Основы законодательства или Основные начала законодательства. Основы законодательства во многом отражали специфику советского государственного и правового устройства, характеризовавшуюся сочетанием централизации и федерализма. Основы законодательства тогда регулировали лишь наиболее важные, принципиальные, требующие единообразного решения для всего государства общественные отношения. Конкретизация этих вопросов, а также регулирование общественных отношений, отнесенных Конституцией СССР к республиканской компетенции, осуществлялись преимущественно в республиканских кодексах. Возможно, учитывая эту специфику, в 1970 г. В.С. Андреев высказал пожелание о разработке и принятии в сфере социального обеспечения именно Основ законодательства СССР о социальном обеспечении. По мнению ученого, этот акт должен был подтвердить завершение процесса создания отрасли права социального обеспечения ${ }^{13}$. Предложения о принятии Основ законодательства о социальном обеспечении высказывались и в более позднее время ${ }^{14}$. Насколько обоснована та или иная форма кодификационного акта для систематизации современного российского законодательства о социальном обеспечении? На наш взгляд, наиболее предпочтительной в этом отношении является точка зрения доктора юридических наук, профессора Зубарева Сергея Михайловича, предлагающего идею создания Социального кодекса Российской Федерации. Тем более что с 2004 г. несколько субъектов Российской Федерации (Белгородская, Омская, Ярославская области, г. Санкт-Петербург) приняли и успешно реализуют подобные законы. По мнению профессора С.М. Зубарева, именно кодекс как законодательный акт сводного характера позволит охватить всю важнейшую часть нормативного материала законодательства о социальной сфере и на основе единых принципов достаточно детально, полно и непосредственно урегулировать соответствующие общественные отношения. Социальный кодекс Российской Федерации станет законом, рассчитанным на длительный период действия и излагающим в систематизированном виде различные правовые нормы. В Общей части Кодекса целесообразно разместить

\footnotetext{
${ }^{12}$ См.: Васильева Ю.В. Кодификация законодательства о социальном обеспечении: основы законодательства или кодекс? // Известия вузов. Правоведение. 2009. № 4. С. 109 - 116.

${ }^{13}$ См.:Андреев В.С. Социальное обеспечение в СССР. М., 1970. С. 29.

${ }^{14}$ Буянова М.O. Социальное обслуживание граждан России в условиях рыночной экономики (теоретико-правовой аспект): Автореф. дис. ... д.ю.н. М., 2003. С. 42.
} 
DOI: $10.7256 / 1811-9018.2014 .12 .13698$

При цитировании этой статьи сноска на dоі обязательна

Человек и государство

нормы, определяющие общие положения о социальной защите граждан Российской Федерации. В Особенной части Кодекса - нормы, устанавливающие единые подходы к оказанию различных видов социальной поддержки различным категориям лиц, оказавшимся в трудной жизненной ситуации. По сути дела, для регламентации каждого из вопросов, которые целесообразно было бы закрепить в Особенной части Кодекса, мог бы быть издан отдельный закон. Связь между этими потенциальными законами в Социальном кодексе Российской Федерации может быть доведена до такой степени совершенства, что позволит говорить о нем как о своеобразном отраслевом своде нормативных предписаний, пронизанных едиными подходами, обобщениями, принципами. Кроме того, Социальный кодекс Российской Федерации может быть использован в качестве базовой площадки для разработки аналогичных законодательных актов субъектов Российской Федерации ${ }^{15}$.
Резюмируя вышесказанное, следует отметить, что законодательство субъектов РФ о социальном обеспечении является составной частью правовой системы РФ и действует в системной взаимосвязи с федеральным законодательством. В настоящее время можно говорить о новом этапе развития регионального нормотворчества в сфере социального обеспечения, негативное влияние на которое оказывает неравномерность экономического положения субъектов РФ, что приводит к законодательному установлению различных условий социального обеспечения для граждан в разных субъектах РФ.

Таким образом, в плоскости правовой реализации остается множество проблем, которые требуют последовательного решения в целях обеспечения достойного уровня жизни и соблюдения гарантированных Конституцией РФ прав и свобод на всей территории Российской Федерации независимо от места проживания.

\section{Библиография:}

1. Андреев В.С. Социальное обеспечение в СССР. М., 1970. С. 29.

2. Буянова М.О. Социальное обслуживание граждан России в условиях рыночной экономики (теоретико-правовой аспект): Автореф. дис. ... д.ю.н. М., 2003. С. 42.

3. Васильева Ю.В. О правовой политике в сфере права социального обеспечения // Трудовое право в России и за рубежом. 2012. № 4. C. 23-26.

4. Васильева Ю.В. Кодификация законодательства о социальном обеспечении: основы законодательства или кодекс? // Известия вузов. Правоведение. 2009. № 4. С. 109-116.

5. Геворкьян Д.П. Становление законодательства Республики Дагестан о социальном обеспечении // Социальное и пенсионное право. 2012. № 2. С.30-32.

6. Добрынин Н.М. Конституционно-правовые аспекты бюджетной обеспеченности реализации социальных гарантий граждан в Российской Федерации и проблема монетизации льгот // Право и политика. 2005. №11. С.4.

7. Закон Тюменской области от 28.12.2004 № 331 «О социальной поддержке отдельных категорий граждан в Тюменской области»// «Парламентская газета «Тюменские известия», № 280-281, 29.12.2004.

8. Зубарев С.М. К вопросу о совершенствовании правовой основы государственного управления в социальной сфере: обсуждаем проект Федерального закона «Об основах социального обслуживания населения в Российской Федерации» // Государственная власть и местное самоуправление. 2013. № 6. С. 31-34.

9. Маленко О.О. Конституционное (уставное) закрепление прав и свобод человека и гражданина в субъектах Российской Федерации: Автореф.дис. ...канд. юрид.наук Ростов н/Д.,2002. С.8.

10. Постановление Правительства РФ от 25.09.2007 № 608 «О порядке предоставления инвалидам услуг по переводу русского жестового языка (сурдопереводу, тифлосурдопереводу)» // Собрание законодательства РФ, 01.10.2007, № 40, ст. 4798.

11. Самарина О.А. Состояние законодательства о социальном обеспечении субъектов РФ: общий анализ// www.territoriaprava.ru.

12. Устав Тюменской области от 30.06.1995 № 6 // Тюменские известия, № 133, 15.07.1995.

13. Численность категорий получателей, размеры денежных выплат и расходы региональных бюджетов 2004 г. и на введение «монетизации» льгот в 2005 г. // Мониторинг социальных аспектов реализации Закона от 22 августа 2004 г. N 122-Ф3 // Аналитический вестник Совета Федерации Федерального Собрания РФ. 2005. № 3. С. 77.

14. Штейнберг М. Горькие «уроки» монетизации льгот. Улучшится ли положение россиян // URL: http:// www.asi.org.ru/ ASI3/ main.nsf/ 0/ 702E418285403167C3257015002EFB93.

\section{References (transliterated):}

1. $\quad$ Andreev V.S. Sotsial'noe obespechenie v SSSR. M., 1970. S. 29.

2. Buyanova M.O. Sotsial'noe obsluzhivanie grazhdan Rossii v usloviyakh rynochnoi ekonomiki (teoretiko-pravovoi aspekt): Avtoref. dis. ... d.yu.n. M., 2003. S. 42.

3. Vasil'eva Yu.V. O pravovoi politike v sfere prava sotsial'nogo obespecheniya // Trudovoe pravo v Rossii i za rubezhom. 2012. № 4. S. 23-26.

4. Vasil'eva Yu.V. Kodifikatsiya zakonodatel'stva o sotsial'nom obespechenii: osnovy zakonodatel'stva ili kodeks? // Izvestiya vuzov. Pravovedenie. 2009. № 4. S. 109-116.

5. Gevork’yan D.P. Stanovlenie zakonodatel'stva Respubliki Dagestan o sotsial'nom obespechenii // Sotsial'noe i pensionnoe pravo. 2012. № 2. S.30-32.

6. Dobrynin N.M. Konstitutsionno-pravovye aspekty byudzhetnoi obespechennosti realizatsii sotsial'nykh garantii grazhdan v Rossiiskoi Federatsii i problema monetizatsii l'got // Pravo i politika. 2005. №11. S.4.

${ }^{15}$ См.: Зубарев С.М. К вопросу о совершенствовании правовой основы государственного управления в социальной сфере: обсуждаем проект Федерального закона «Об основах социального обслуживания населения в Российской Федерации» // Государственная власть и местное самоуправление. 2013. № 6. С. 31 - 34 . 
DOI: $10.7256 / 1811-9018.2014 .12 .13698$

При цитировании этой статьи сноска на доі обязательна

\section{Право и политика $12(180) \cdot 2014$}

7. Zubarev S.M. K voprosu o sovershenstvovanii pravovoi osnovy gosudarstvennogo upravleniya v sotsial'noi sfere: obsuzhdaem proekt Federal'nogo zakona "Ob osnovakh sotsial'nogo obsluzhivaniya naseleniya v Rossiiskoi Federatsii" // Gosudarstvennaya vlast' i mestnoe samoupravlenie. 2013. № 6. S. 31-34.

8. Malenko O.O. Konstitutsionnoe (ustavnoe) zakreplenie prav i svobod cheloveka i grazhdanina v sub"ektakh Rossiiskoi Federatsii: Avtoref.dis. ...kand. yurid.nauk Rostov n/D.,2002. S.8.

9. Samarina O.A. Sostoyanie zakonodatel'stva o sotsial'nom obespechenii sub"ektov RF: obshchii analiz// www.territoriaprava.ru.

10. Shteinberg M. Gor'kie "uroki” monetizatsii l'got. Uluchshitsya li polozhenie rossiyan // URL: http:// www.asi.org.ru/ ASI3/ main.nsf/ 0/ 702E4 18285403167 C3257015002EFB93. 